\title{
The Differences of School Students' Styles and Their Teaching Strategies
}

\author{
Zarean Bakshi \\ Department of Education, St. Aloysius College, Jabalpur, India \\ zareenbakshi21179@gmail.com \\ zareenbaksh@staloysiuscollege.ac.in
}

\begin{abstract}
The main purpose of this research paper is to determine the varied aspects of learning style used by the school students. Basically we cover the four types of learning style showing the various preference of learning adopted by the students. In this paper the main aim is to find that how an individual is different from the other and how they perceive learning. In this research paper we chose four types of styles (Visual, Auditory, Reading and Kinesthetic) abbreviated as VARK and a brief questionnaire is also prepared to collect the information of varied learning aspects adopted by the students in different situation. In this questionnaire main focus is on higher secondary school students and to find that how individual is different from the other in terms of the mode of learning. The result found is that most of the participants preferred visual and reading styles of learning. Advocacy of the paper is provided at the end of the study.
\end{abstract}

Keywords: Learning style, Visual, Auditory, Reading styles

\section{Introduction}

Learning style is the manner by which an individual naturally get, holds and recovers data. Learning style is the manner by which an individual naturally acquires, collects and retrieves information. The amount of information gathered in class is affect learner cognitive ability, logical thinking and his prior knowledge. Every individual has his own style of learning. Someone learns by reading and others learn by seeing or listening. The acquisition of knowledge is highly influenced by the learner interest in the subject. There are various models of perceiving information. The learner could one Style of learning or a combination of different styles. Hence every learner possesses a unique set of learning styles. Learners may use Different learning styles at different time and as per different frame of mind. Neil. D. Fleming and E. Mills in 1992 described four modalities of student learning. These are four different learning style represented by the acronym VARK.

\section{1) Visual Style}

Such students process it better in form. They create a picture in their mind of what is being told or is written in texts. When information is presented to them in graphics, pictures, table or charts, diagrams they easily gathered information without to be written in text.

\section{2) Auditory style}

Auditory learners tend to hear information rather than reading or seeing. These types of learner focus on hearing ability.

\section{3) Reading/ Writing style}

These learners love to read and write. They have excellent command over vocabulary and they prefer to stay quiet and read at a corner. They make notes what they read in a particular time and this type of learner use conventional style for studying.

\section{4) Kinesthetic learning Style}

This is the most commonly used and easiest learning style. Experience is the greatest teachers. They learn by touch, insight by movement and by imitation. Such learners have difficulty in focusing and don't pay attention in important class.

\subsection{Objectives}

1) To explore the preference of learning style of the higher secondary school students.

2) To explore the students learning styles of different chronological age and mental age.

Now a day, because of pandemic people are staying at home and mainly using internet for online studies, office work, research work etc. These days online survey or internet survey has become one of the most popular means for collect data or information online. In online method a set of survey questions is sent out to the members of a particular target and respondents receive online surveys via various mediums such as E - mail, embedded over website and social media. Online forms are a modern and effective way to conduct surveys. Online form allows researchers to collect critical data from the target audience. For example, Google form. It is survey administration software included as part of the free, web based Google editors includes Google docs, Google sheets, Google slides, Google drawings, Google sites and Google keep. Google form is only available as a web application. The app allows users to create and edit surveys online while collaborating with other users in real time. The collected information can be automatically entered into spreadsheets. The primary reason for the growth seen in the implementation of online survey is that they are extremely low cost and conducting an online survey in convenient due to the sheer magnitude of reach. Over the past decades, researchers have started prefer conducting surveys using an online survey tool as they can send out surveys from the desktop or laptop and targeted audience can respond to these surveys whenever possible. 


\subsection{Questionnaire Techniques}

A questionnaire technique is that tool in research which comprises the questionnaire sheet. It aim is collecting information from the individual. It allows relatively inexpensive rapid and a well organised method of getting wide or a large number of respondents and in this data can be collected quickly because it would not need to be presented when it was completed. The questionnaire in learning style is prepared to find out the preference of the students as most of them were unaware of this, so questionnaire will help to identify their learning style mode. They are made to help respondents to find which learning style to learn. In this they select the option that most relatively related to their own preference. This questionnaire technique is either in the form.

- Multiple choices

- Rating scale question.

- Matrix question.

- Dropdown question.

- Open ended question.

- Close ended question.

- Ranking question etc

In this research paper we follow the multiple choice question because most of the time this pattern follows and in every research it shows a quick response and data is collected immediately without any error. It shows clear result made by the respondents and through this data the researcher find easy to make the related bar diagram and pie charts.

\subsection{Data Analysis}

After the questionnaire technique the next step or stage is data analysis in which it is found that most of the individual use to prefer visual learning style most of the times and the least style which is used by individual is kinesthetic style. While doing analysis it is found that most of the higher secondary students used to prefer visual learning style most of the time. The style which is used by individual in second option is reading learning and third is auditory which third least style used by the students. For example

Q1. What kind of learner are you?

\begin{tabular}{|c|c|}
\hline Styles & Percentage \\
\hline Visual & 54.8 \\
\hline Auditory & 7.1 \\
\hline Reading and writing & 35.7 \\
\hline Kinesthetic & 2.4 \\
\hline
\end{tabular}

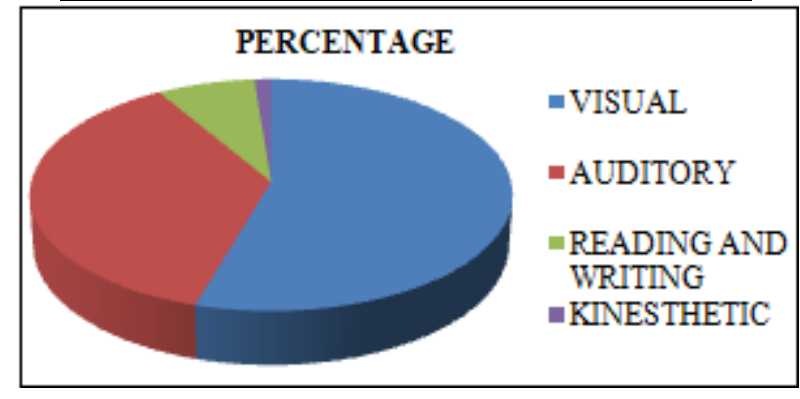

\begin{tabular}{|c|c|c|}
\hline Options & Count & Percent \\
\hline Visual & 21 & 52.5 \\
\hline Auditory & 3 & 7.5 \\
\hline Reading & 15 & 37.5 \\
\hline Kinesthetic & 1 & 2.5 \\
\hline
\end{tabular}

\section{Result}

The next step after the data analysis is result which is the most important stage of a research which shows the analysis of a data through a pictorial graph and pie chart.

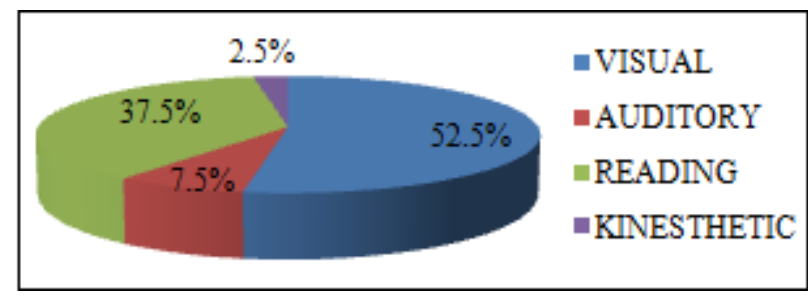

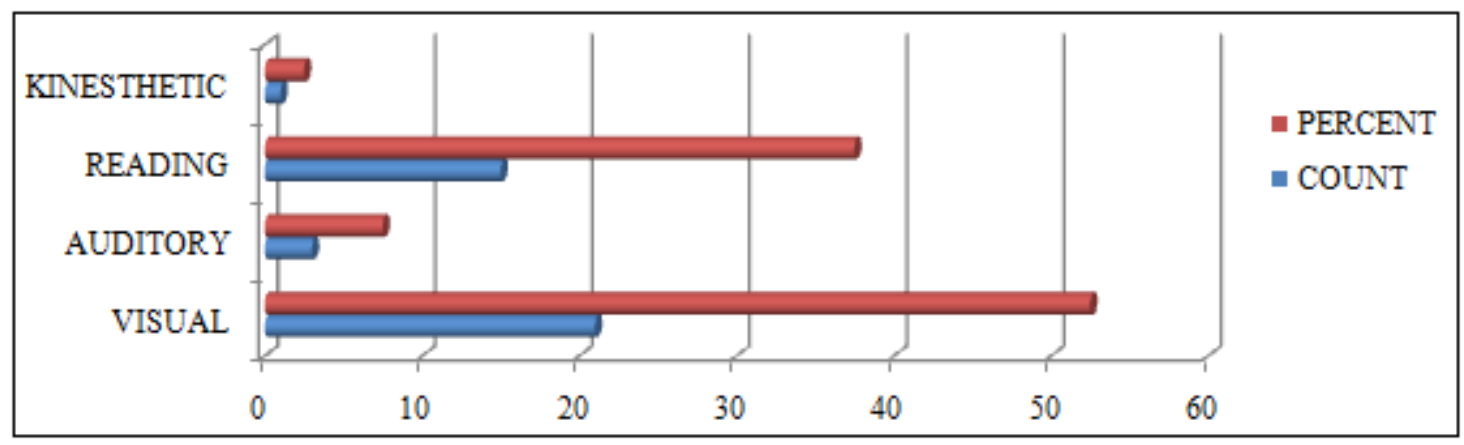

\section{Suggestion}

Suggestion is the last stage of our research paper in which some suggestion is given regarding our topic and what will be the necessary points from which that particular activity will be successful. Some of the points are: -

- Topic should be discuss in the class with the students so that whatever style is used by student to make their learning effective.
- Use charts and diagrams for explaining the particular session to make their visual style of learning effective.

- Always assign different activities to the students so that they can use different modes of learning style in particular time. 


\section{Conclusion}

Learning style is a very important tool in understanding one own self and increase the pace of understanding and work on it with full enthusiasm. With this form of education and learning style, student will able to understand each and every aspect of learning. In an earlier part we have cover importance of VARK in learning and it seems that it is important in every part of education and it becomes one of the most important elements of learning. Learning style is not important only for students but it is much helpful for teachers because while teaching in school teacher also use different learning style to make their learning effective. So learning style is an important factor in students learning.

\section{References}

[1] http: //www.questionpro. com/blog/what - are - online surveys/

[2] http: //www.jotform. com/data - collection - methods/

[3] http: //www.en. wikipedia. org/wiki/google - forms

[4] Bansal, S. (2012), Effective learning for children with learning strategies, edutracks, 11 (B).

[5] Victoria C, Alan C, VARK Learning styles self assessment questionnaires 2005.

[6] LathaVenkatesan. An analysis of learning style in higher secondary students. 